MATEC Web of Conferences 13, 02028 (2014)

DOI: $10.1051 /$ matecconf/ 20141302028

(C) Owned by the authors, published by EDP Sciences, 2014

\title{
Portable Thermoelectric Power Generator Coupled with Phase Change Material
}

\author{
Chong C. Lim ${ }^{1, a}$, Hussain H. Al-Kayiem ${ }^{1}$ and Chin Y. Sing ${ }^{1}$ \\ ${ }^{1}$ Mechanical Engineering Department, UniversitiTeknologi PETRONAS, Bandar Seri Iskandar, 31750 \\ Tronoh, Perak, Malaysia
}

\begin{abstract}
Solar is the intermittent source of renewable energy and all thermal solar systems having a setback on non-functioning during the night and cloudy environment. This paper presents alternative solution for power generation using thermoelectric which is the direct conversion of temperature gradient of hot side and cold side of thermoelectric material to electric voltage. Phase change material with latent heat effect would help to prolong the temperature gradient across thermoelectric material for power generation. Besides, the concept of portability will enable different power source like solar, wasted heat from air conditioner, refrigerator, stove etc, i.e. to create temperature different on thermoelectric material for power generation. Furthermore, thermoelectric will generate direct current which is used by all the gadgets like Smartphone, tablet, laptop etc. The portable concept of renewable energy will encourage the direct usage of renewable energy for portable gadgets. The working principle and design of portable thermoelectric power generator coupled with phase change material is presented in this paper.
\end{abstract}

\section{Introduction}

Thermoelectric generator (TEG) is a solid-state device that converts heat to electricity. The modern thermoelectric module consists of thermoelectric n-type and p-type connected in series. Heat flow parallel across the thermoelectric elements and generate voltage through Seebeck effect. The voltage is proportional to the temperature difference, $\Delta \mathrm{T}$. [1]

Renewable energy (RE) is energy, which comes from natural recourses such as sunlight, wind, biomass, geothermal heat etc. Currently the green portable power generator in the market is mainly based on photovoltaic (PV) technology which needs light (normally sunlight) to generate electricity. But solar is the intermittent source of energy. It is only available for few hours in a day. Besides, it is very dependant on the weather and season. The rules of solar on the thermal solar systems are comprehensively reported by [2,3]. Phase change material (PCM) had been widely studied in the thermal storage application to partly resolve the problem of solar intermittent. It can be classified to three main categories: organic, inorganic and eutectic. PCM can store the energy in sensible heat and latent heat. [4,5] have presented detailed information on the usage of PCM and the integration with solar system.

Researchers had worked on the concept of TEG coupled with phase change material for the sensor and actuators $[7,8]$. It is used for microwatt and micro voltage applications. In this paper, the design is

\footnotetext{
${ }^{\text {a }}$ Corresponding author : ccllim78@gmail.com
}

This is an Open Access article distributed under the terms of the Creative Commons Attribution License 2.0, which permits unrestricted use, distribution, and reproduction in any medium, provided the original work is properly cited. 
aimed to generate milli-watt and $2 \mathrm{~V}$ to $5 \mathrm{~V}$ of voltage for portable electronic device charging. Besides, the concept and design of portable TEG energy harnessing device are explored in this paper.

\section{Concept of portable thermoelectric power generator}

Figure 1 shows the concept of portable TEG coupled with PCM. Because of the portability, multiple heat sources like solar heat, wasted heat from air conditioner, refrigerator, stove, hot water etc. can be used as heat input for TEG. While heat flow from ambient environment through TEG module to PCM, PCM temperature will rise and electric voltage generated. PCM solid will melt as the PCM reach the melting temperature. After PCM melts, PCM liquid temperature will continue rise as the heat continue to flow in. Energy is stored in the PCM as sensible and latent heat. This is known as PCM charging mode. Now with the absence of heat source, PCM can act as heat source and release heat to the colder ambient like air conditioned room, cold water, fan cooling etc. With the same principle, electric voltage is generated when heat flow from PCM through TEG module to ambient environment. PCM liquid temperature will drop and solidify when it reach the crystallization temperature. This is known as PCM discharge mode. This will able to have longer hours of power generation compared with portable PV power generation which is only depend on sunlight.

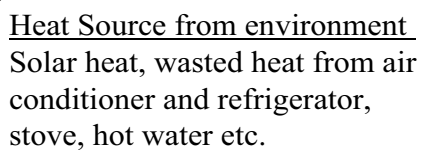

\section{Cold environment}

Air conditioned room, cold water, fan cooling, night, inside refrigerator etc.
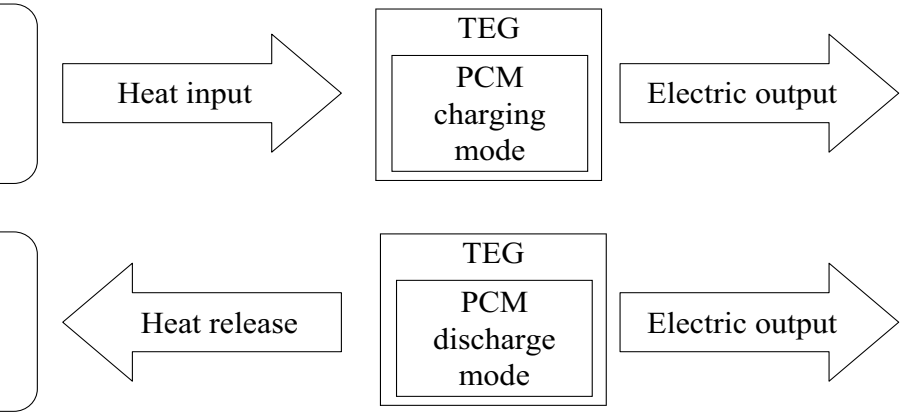

Figure 1. Concept of portable TEG coupled with PCM

\section{Design and construction}

There are several different designs for this concept. Two different designs are presented in this paper.

\subsection{Type A design}

Figure 2 shows Type A design which consists of cover glass where there is air in between the absorber and cover glass. The cover glass will allow solar radiation to pass through and reduce heat loss of absorber by convection and radiation. This construction is similar to flat panel solar collector. But in this design, the cover glass is removable. It serves the purpose of direct conduction and convection heat transfer from heat source to absorber during PCM charging mode. Besides, removing cover glass will help for absorber cooling during PCM discharge mode.

TEG module will be sandwiched between absorber and heat sink. Both are good thermal conductivity metals like Aluminum and Copper which have thermal conductivity range from $200 \mathrm{~W} /(\mathrm{mK})$ to $400 \mathrm{~W} /(\mathrm{mK})$. TEG material selection is very much based on the operating temperature of application. Bismuth Telluride TEG material is the best material available in the commercial market for this application where operating temperature is less than $100^{\circ} \mathrm{C}$. The absorber has a selective surface for solar radiation. It has a high value of solar radiation absorptance $(\alpha)$ on solar wavelength and low value of long wave thermal radiation emittance $(\varepsilon)$. Today, solar absorber is made by black chrome electroplating, aluminum anodizing [2,3] and even using physical vapor deposition 
(PVD) which is the latest technology to deposit diamond like carbon (DLC) on absorber [6]. The layer of TEG module will be filled with polyurethane (PU) foam that acts as insulator. After the metal heat sink, it is PCM layer and then followed by PU foam to reduce heat loss of PCM to surroundings. Paraffin wax organic phase change material proposed in this design because it has the non-corrosive characteristic. So, it is safe to use in the electronic product. Besides, it has high thermal energy storage capacity and long life product with stable performance through the phase change cycles.

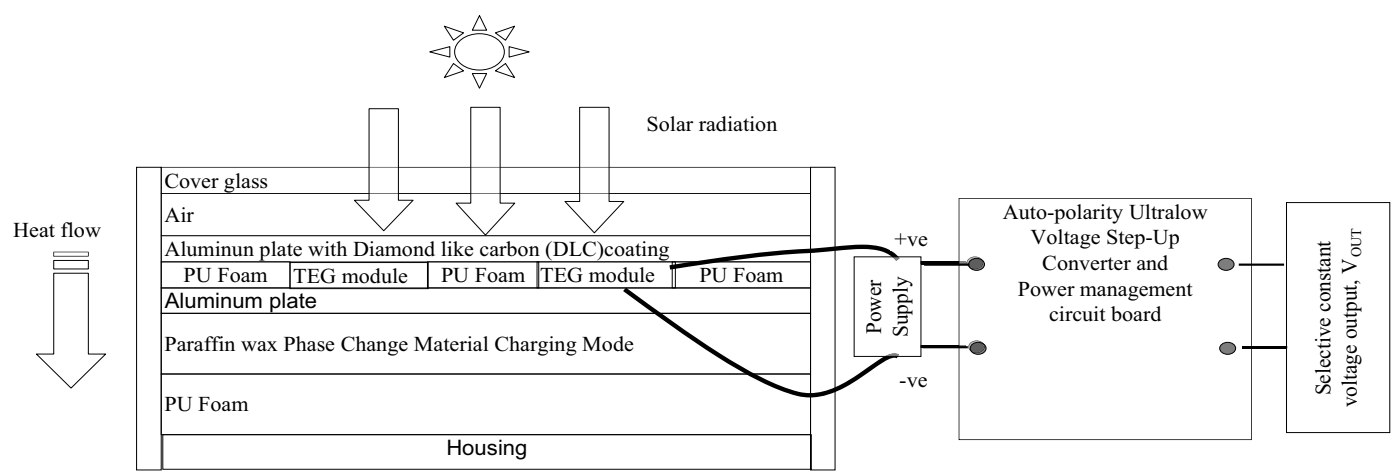

Figure 2.Type A design and construction of portable TEG (PCM charging mode)

When the absorber is exposed to solar radiation, absorber will absorb solar radiation energy and the temperature will rise quickly due to the low specific heat capacity of metal. Instead, the temperature of PCM with much larger specific heat capacity and is hidden from solar radiation will rise slowly compare with absorber. By this, heat will flow from absorber to PCM through TEG module and it will create a temperature difference across the TEG module. Furthermore, when PCM reach the melting temperature, it will remain at the melting temperature for a certain period. This will create a larger temperature difference on the hot side and cold side of TEG module. Directly the TEG module will generate positive voltage. This is the charging mode of PCM and the energy will be stored in the form of sensible and latent heat.

During evening or night, PCM temperature will be more than the absorber temperature. This is the discharge mode of PCM. Figure 3 shows that cover glass can be removed during PCM discharge model. It will create convection cooling for absorber and create larger temperature gradient across TEG module. Now the heat flow from PCM to absorber through PCM module and directly TEG module will generate negative voltage as shown in figure 3, which is the reverse voltage polarity of TEG module in the PCM charging mode.

TEG will generate a wide range of fluctuation low voltage output with dual polarity. In order to harness this energy for the usage of charging modern portable gadgets, TEG need to connect with auto polarity ultra-low voltage step up converter and power management circuit board. This circuit board will provide a constant voltage output $(2.2 \mathrm{~V}, 3.3 \mathrm{~V}, 4.1 \mathrm{~V}$ and $5 \mathrm{~V})$ from both polarity and fluctuation low voltage input $(50 \mathrm{mV} \sim 400 \mathrm{mV})$.

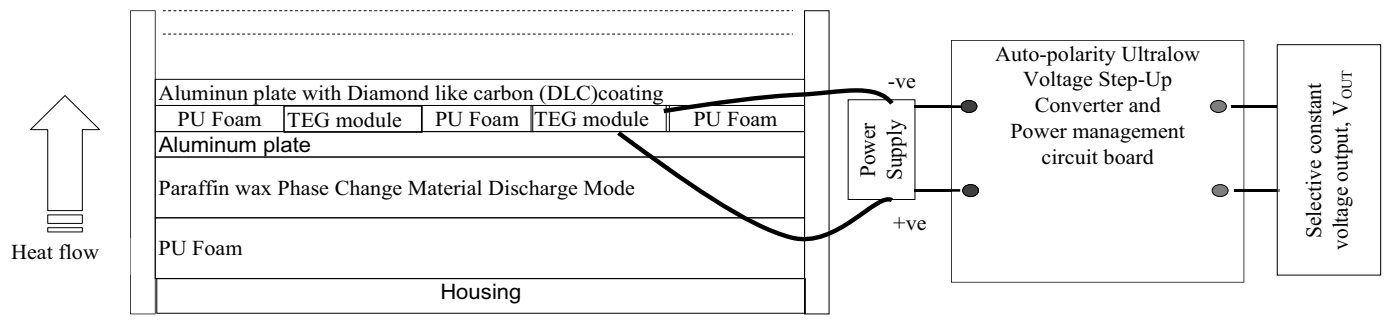

Figure 3.Type A design and construction of portable TEG (PCM discharge mode)

\subsection{Type B design}

Figure 4 shows the Type B design of portable TEG. Removable glazing glass and the air layer to separate glazing and absorber are the same for both types of design. The main difference of Type B design is the placement of PCM. In Type B design, absorber is made by the hollow extruded 
Aluminum with solar selective surface. PCM is packed inside the hollow extruded Aluminum. TEG modules are sandwiched between the absorber and heat sink. Type B design will use Aluminum heat sink with fins for natural or force convection cooling. When absorber exposes to solar radiation, heat will flow to PCM and heat sink through TEG modules at the same time. This is PCM charging mode. During PCM discharge mode, heat will flow from PCM to absorber and heat sink through TEG modules. Heat will always flow from one direction, which is from absorber to heat sink. So, there is no reverse polarity for TEG voltage output in this design.

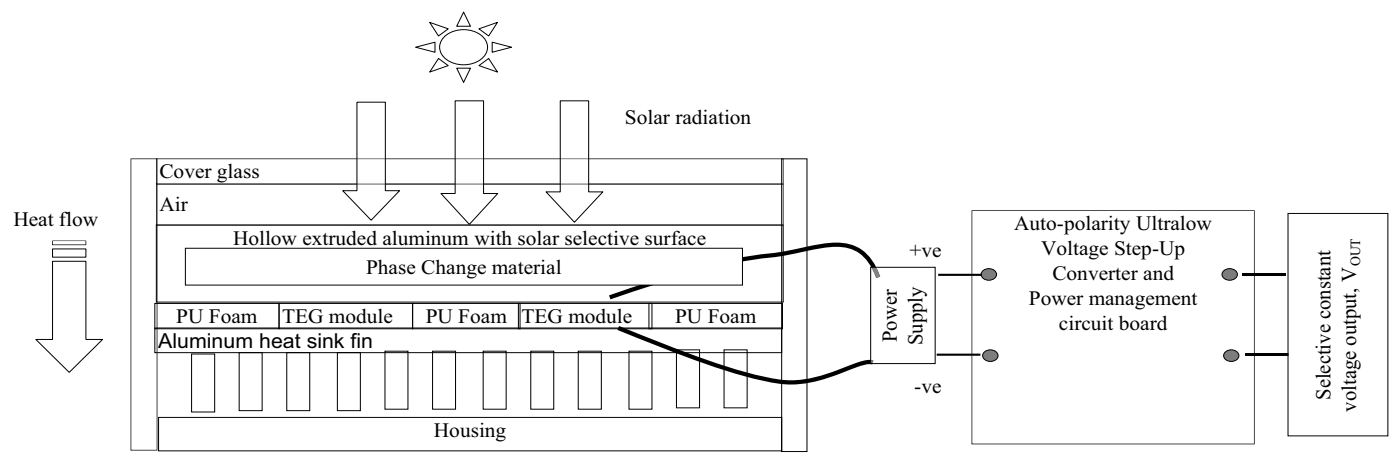

Figure 4.Type B design and construction of portable TEG

\section{Discussions}

Concept and design of portable TEG coupled with PCM shows that it is practical to prolong the power generation in a day compared with PV technology. This is because multiple heat sources can be used by portable TEG for power generation. Besides, energy can be stored in PCM and act as a heat source for power generation.

Two different designs approach are presented. Both designs have advantage and disadvantage. Table 1 give a brief summary for comparative advantage and disadvantage of both design.

Table 1.Comparative advantage and disadvantage of Type A and B design

\begin{tabular}{|c|c|c|l|}
\hline Item & TYPE A & TYPE B & \multicolumn{1}{c|}{ Explanation } \\
\hline Cost & Low & High & $\begin{array}{l}\text { The hollow extruded and heat sink fins used in Type B } \\
\text { design will increase the cost due to the complicated shape } \\
\text { for manufacture compare with the flat plate. }\end{array}$ \\
\hline $\begin{array}{c}\text { Start up time } \\
\text { for power } \\
\text { generation }\end{array}$ & Fast & Slow & $\begin{array}{l}\text { When Type A and B design expose to sunlight at the same } \\
\text { time, Type A design will first to have power voltage output } \\
\text { because the heat direct flow from absorber to heat sink. In } \\
\text { Type B design, portion of energy is used to heat up the } \\
\text { PCM. }\end{array}$ \\
\hline $\begin{array}{c}\text { Maximum } \\
\text { voltage output }\end{array}$ & Low & High & $\begin{array}{l}\text { Type B design can have the higher maximum voltage output } \\
\text { because of the forced convection cooling on the heat sink } \\
\text { fins. }\end{array}$ \\
\hline $\begin{array}{c}\text { PCM charging } \\
\text { time }\end{array}$ & Slow & Fast & $\begin{array}{l}\text { Type B design will have the fast PCM charging because it } \\
\text { direct contact with absorber. }\end{array}$ \\
\hline $\begin{array}{c}\text { PCM discharge } \\
\text { time }\end{array}$ & Slow & Fast & $\begin{array}{l}\text { Type B design with heat sink fins cooling will cause the } \\
\text { PCM discharge faster. }\end{array}$ \\
\hline $\begin{array}{c}\text { Power } \\
\text { management }\end{array}$ & Complicated & Simple & $\begin{array}{l}\text { Type B design has a constant polarity voltage input will } \\
\text { have a more simple power management compare with dual } \\
\text { polarity voltage input in Type A design. }\end{array}$ \\
\hline
\end{tabular}




\section{Conclusion}

The concept of portable TEG coupled with PCM is a comprising alternative to current portable solar PV power generator. Two different designs approach are presented in the paper. Mathematical model, simulation, prototype fabrication and experiment are the methodology for the continuing research of this paper.

\section{Acknowledgement}

The authors acknowledge Universiti Teknologi PETRONAS for sponsoring the research under (STIRF-0153AA-C10).

\section{References}

1. G. Jeffrey Synder. Small Thermoelectric Generator. The electrochemical society interface. (2008)

2. J.A Duffie, W.A. Beckman. Solar Engineering Thermal Process. John Wiley and Sons.(2006)

3. Soteris. A. Kalogirou. Solar Energy Engineering Processes and Systems. Elsevier Inc.(2009)

4. Atul Sharma, V.V. Tyagi, C.R. Chen, D. Buddhi. Renewable and SustainableEnergyReviews13, 318-345. (2009)

5. Francis Agyenim, Neil Hewitt, Philip Eames, MerrynSmyth.. Renewable and SustainableEnergyReviews14, 615-628. (2010)

6. SS Thinchev, P I Nikolova, Y T Dyulgerska. Journal of Physic: Conference series 223. (2010)

7. Amen Agbossou, Qi Zhang, Gael Sebald, Danel Guyomar. Part I: Theoreticalanalysis. Sensors and Actuators A 163, 277-283. (2010)

8. Qi Zhang, Amen Agbossou, Zhihua Feng, Mathieu Cosnier. Part II: Experiment analysis. Sensor and Actuators A 163, 284-290. (2010) 